\title{
Life Style Factors Influencing Immunotoxic Effects Detected on Peripherial Blood Lymphocytes of Health Personnel Exposed to Anesthetic Gas
}

\section{Anna Biró ${ }^{1 *}$ and Anna Tompa ${ }^{1,2}$}

${ }^{1}$ National Institute of Chemical Safety, 1096, Nagyvárad tér 2, Budapest, Hungary

${ }^{2}$ Institute for Public Health, Semmelweis University, Faculty of Medicine, Budapest, Hungary

\begin{abstract}
In this study, changes in the immune phenotype of 127 subjects exposed to anesthetic gases from health services were measured by flow cytometry. The data was compared to healthy, non-exposed controls. We supposed that there is a relationship between health risk for the personnel exposed to anesthetic gases and the alteration of the measured immune parameters in the presence or absence of confounding factors such as smoking and alcohol consumption. In the group of health personnel exposed to anesthetic gases, we found a statistically significant increase in the ratio of CD25+/CD8+ cells - activated cytotoxic T cells - compared to the control. In those workplaces, where protective measures were strictly adhered to (with quality assurance) the activation of lymphocytes was at control level, however, where there was no quality assurance, activation of lymphocytes increased significantly compared to the control. In the anesthetic gas exposed smokers, there was a statistically significant shift in the T cell subpopulations: the percentage of helper T cells increased, while the percentage of cytotoxic T cell decreased, leading to an elevated Th/ Tc ratio compared to the nonsmokers. Our results suggest that our biomarkers can be useful in tracking occupational/ environmental immunotoxic effects. Smoking as a confounding factor has to be taken into account when assessing occupational exposures.
\end{abstract}

Keywords: Occupational exposure; Anesthetic gases; Lymphocyte phenotype; Lymphocyte subpopulations; Activation markers

\section{Introduction}

According to epidemiological data, occupational exposure of workers to waste anesthetic gases in the operating rooms of hospitals may cause adverse effects on the health of personnel. Excess of deaths from pancreatic cancer and from lymphoid and reticular-endothelial malignancies have been reported [1,2]. Especially nitrous oxide may result in hematological changes and causes peripheral neuropathy [3]. The precise mechanisms of anesthetic action of these chemicals are not fully understood, although it is a hot topic of research. There is some evidence of their effects on neurotoxicity and neuron -protection as well [4]. In some early studies, it has been reported that high anesthetic concentrations of halothane may result serious hepatic failure [5]. The long term, chronic effects of anesthetic gases studied in exposed populations include cancer, and liver and kidney disease, but the findings are inconsistent [6]. Some of international epidemiological studies showed a positive relation between exposure to anesthetics and the frequency of spontaneous abortions $[7,8]$.

As the exposure to chemicals may induce alterations in the function of lymphocytes we started immunotoxicological investigations, aiming primarily at phenotypical measurements $[9,10]$. The subpopulations of lymphocytes can be distinguished by immune-phenotype, using cellsurface markers. Immune-phenotyping is a method listed by WHO as one of the methods that can be used to characterize immune-toxicity [11]. Our approach is novel in that besides measuring lymphocyte subpopulations, we also detected the activation of lymphocytes, which has not been assessed in occupational exposure to anesthetics. Activation of lymphocytes can be assessed with the use of activation markers such as CD25 (interleukin-2 receptor) and CD71 (transferrin receptor).

In the last 12 years, we have investigated more than 2500 subjects exposed to different toxic substances. In this paper, we discuss the immunological monitoring of 127 subjects exposed to anesthetic gases. Their data were compared to controls matched in age and gender, occupationally not exposed to known substances. We have also assessed how confounding factors related to lifestyles, namely smoking and alcohol consumption can alter the measured immune parameters.

Anesthetic gases escape into the ambient air mainly from the anesthetic breathing system but there are many other important sources of anesthetic pollution. These include the filling of vaporizers, inhalational induction techniques, leaks around the patient's facemask, leaks from monitoring equipment and loose-fitting or perishing equipment [12]. Anesthetic gas exposure often exceeds set safety limits, especially in the case of pediatric anesthetists, or when no proper ventilation has been installed in operating theaters. The type of breathing system used and scavenging seem to influence this exposure, although surprisingly, not the induction technique or method of airway control [13]. Several studies have dealt with the immunological status of health personnel chronically exposed to trace amounts of volatile anesthetics in operating theatres. But the studies are not easily comparable due to the heterogeneity of exposed groups, considerable differences in gas type and levels, the great variability in immune parameters examined, and the methodology of the studies. Many aspects of the immune response have been evaluated with contradictory results, some studies have not found any changes in the investigated immune parameters [14-16] and both inhibition and stimulation has been reported depending on the cell type or function [17-19].

*Corresponding author: Anna Biró, Department of Cytogenetics and Immunology, National Institute of Chemical Safety, Budapest, $\mathrm{H}-1097$ Budapest Nagyvárad tér 2., Hungary, Tel: 36-1- 476-1111; Fax: 36-1-476-1227; E-mail biro.anna@okbi.antsz.hu

Received April 30, 2013; Accepted May 30, 2013; Published June 03, 2013

Citation: Biró A, Tompa A (2013) Life Style Factors Influencing Immunotoxic Effects Detected on Peripherial Blood Lymphocytes of Health Personnel Exposed to Anesthetic Gas. Clin Exp Pharmacol S4: 004. doi:10.4172/2161-1459.S4-004

Copyright: @ 2013 Biró A, et al. This is an open-access article distributed under the terms of the Creative Commons Attribution License, which permits unrestricted use, distribution, and reproduction in any medium, provided the original author and source are credited. 


\section{Materials and Methods}

\section{Subjects}

Altogether 127 nurses exposed to anesthetic gases were investigated. Their results were compared to 33 healthy controls, occupationally not exposed to known substances.

A physician to collect data on age, medication, smoking and drinking habits, as well as medical and work histories including exposure to known or suspected toxicants, occupational history including duration of exposure, and the use of protective devices during work, interviewed all subjects. The anesthetic gases used in operating theaters were Sevoflurane, Isoflurane, Nitrous oxide, and in some cases Halothane. Additionally, some of the subjects could be exposed to X-rays as well. Active smoker subjects were considered "Smokers". "Drinkers" consumed no more than 80 g pure alcohol regularly (a liter of beer or equivalent). Heavy drinkers were excluded. With the informed subjects' written permission, blood samples were collected by venipuncture. The samples were processed for immunological analysis and, to assess health status, for a routine clinical check-up including hematology, liver and kidney function tests.

\section{Immune phenotyping of peripheral blood lymphocytes (PBL) by flow cytometry}

Heparinized whole blood was mixed and incubated at room temperature for 20 minutes with the appropriate amount of Fluorescein Isothiocyanate (FITC), Phycoerythrin (PE), Peridinin-ChlorophyllProtein Complex (PerCP), or Allophycocyanin (APC) labelled monoclonal antibodies against surface antigens. The erythrocytes were removed by lysis with the addition of FACS Lysing solution (Becton Dickinson). After washing with Phosphate Buffered Saline (PBS), samples were analyzed within 4 hours after labeling, or fixed with $2 \%$ paraformaldehyde. The studied antigens were: CD3, CD4, CD8, CD19, CD25, CD45, CD56 and CD71. The monoclonal antibodies were purchased from Becton Dickinson. Three and four-color analysis was performed on a Becton Dickinson FACSCalibur flow cytometer. The following monoclonal antibody combinations were used: (1) CD25FITC / CD8-PE / CD3-PerCP / CD4-APC; (2) CD56-FITC / CD3PerCP / CD45-APC; and (3) CD71-FITC / CD3-PerCP / CD19-APC. Standard forward and side scatter gating combined with CD45 was used to separate leukocyte populations and to set the lymphocyte gate. $\mathrm{CD} 3$ was used as $\mathrm{T}$ cell marker, helper $\mathrm{T}$ cells were characterized by $\mathrm{CD} 3+/ \mathrm{CD} 4+$ phenotype, cytotoxic T cells by CD3+/CD8+ phenotype, $\mathrm{NK}$ cells as CD3-/CD56+ phenotype and B lymphocytes were characterized as CD19+ cells. Data for at least 10000 leukocytes per sample were acquired, CellQuest Pro Software (Becton Dickinson) was used for analysis.

Phenotypes are expressed as percentage of positive cells of a given lymphocyte subpopulation e.g. CD71+/CD19+ denotes the percent of CD71 positive $B$ cells.

\section{Statistical analysis}

Statistical differences between the studied groups were analyzed by Student's t-test, $\mathrm{p}<0.05$ was considered as statistically significant.

\section{Results}

In the group of health personnel exposed to anesthetic gases, we found a statistically significant increase in the ratio of CD25+/CD8+ cells - activated cytotoxic T cells - compared to the control (Figure 1). In the anesthetic gas exposed smokers, there was a statistically significant shift in the $\mathrm{T}$ cell subpopulations, namely the percentage of helper $\mathrm{T}$ cells increased, while the percentage of cytotoxic $\mathrm{T}$ cell decreased, leading to an elevated $\mathrm{Th} / \mathrm{Tc}$ ratio compared to the nonsmokers (Table 1 and Figure 2). Smoking also caused changes in white cell blood counts. The leukocyte count increased in smokers compared to nonsmokers $(6.98 \pm 0.35 \mathrm{G} / \mathrm{L}$ and $5.65 \pm 0.16 \mathrm{G} / \mathrm{L}$ respectively, $\mathrm{p}=0.001)$ lymphocyte counts increased $(1.89 \pm 0.08 \mathrm{G} / \mathrm{L}$ and $1.62 \pm 0.06 \mathrm{G} / \mathrm{L}$ respectively, $\mathrm{p}=0.007)$, while neutrophil counts decreased $(4.75 \pm 0.03$ $\mathrm{G} / \mathrm{L}$ and $3.71 \pm 0.12 \mathrm{G} / \mathrm{L}$ respectively, $\mathrm{p}=0.002$ ).

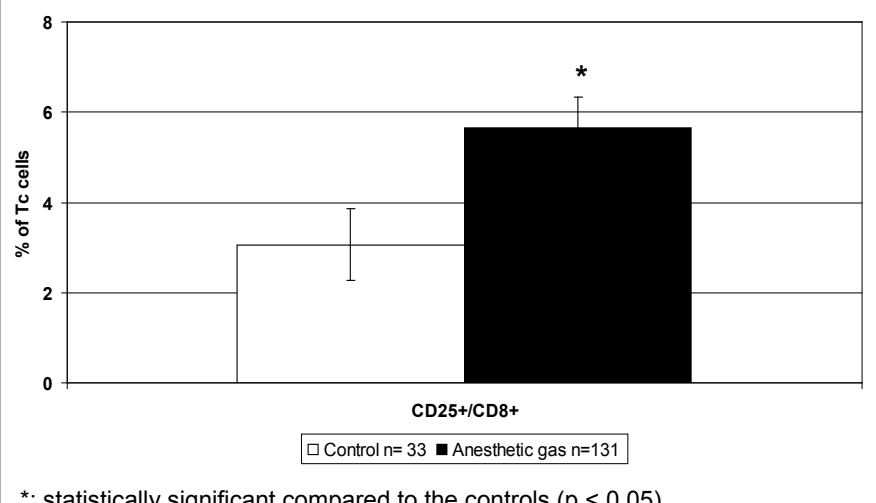

Figure 1: The effect of anesthetic gas exposure on activation of lymphocytes. The mean $\% \pm \mathrm{SE}$ is given for each group.

\begin{tabular}{|c|c|c|c|c|c|}
\hline Group & $\mathbf{n}$ & $\begin{array}{c}\text { Mean age } \\
\text { year } \mathbf{\text { SE }}\end{array}$ & $\begin{array}{c}\text { Mean duration } \\
\text { of exposure } \\
\text { year } \mathbf{\pm} \text { SE }\end{array}$ & $\begin{array}{c}\text { Smokers } \\
\%\end{array}$ & $\begin{array}{c}\text { Drinkers } \\
\%\end{array}$ \\
\hline Control & 33 & $39.9 \pm 1.4$ & - & 26.6 & 42.4 \\
\hline Anesthetic exposed & 127 & $40.0 \pm 0.8$ & $14.8 \pm 0.9$ & 39.4 & 65.4 \\
\hline Anesthetics+ X-ray & 70 & $39.4 \pm 1.2$ & $13.9 \pm 1.2$ & 40.0 & 70.0 \\
\hline Only anesthetics & 57 & $40.7 \pm 1.0$ & $15.9 \pm 1.3$ & 38.6 & 63.2 \\
\hline Halothane & 57 & $40.0 \pm 1.3$ & $14.9 \pm 1.3$ & 40.4 & 64.9 \\
\hline No halothane & 70 & $40.0 \pm 1.1$ & $14.7 \pm 1.2$ & 34.3 & 62.9 \\
\hline Quality control & 87 & $39.6 \pm 1.0$ & $14.6 \pm 1.0$ & 33.3 & 63.2 \\
\hline No quality control & 41 & $40.9 \pm 1.5$ & $15.2 \pm 1.6$ & 51.2 & 73.1 \\
\hline
\end{tabular}

a: active smoker

$\mathrm{b}$ : less than $80 \mathrm{~g}$ alcohol

Table 1: Demographic data of anesthetic gas exposed nurses and unexposed controls.

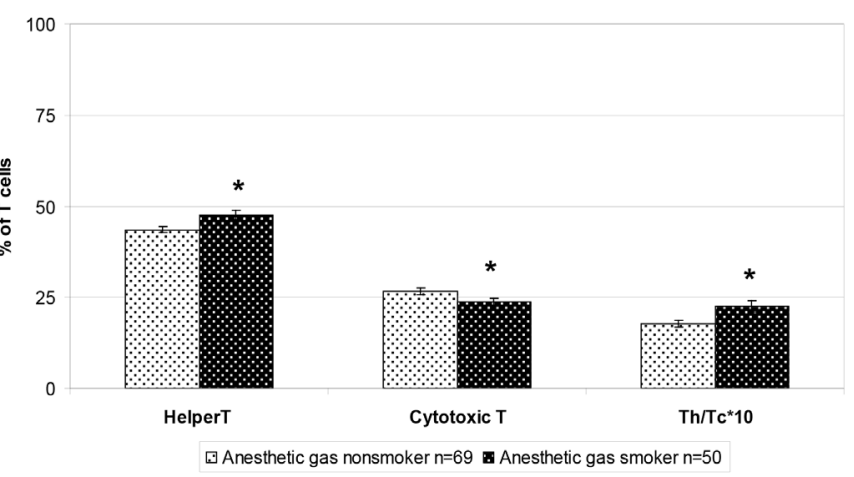

*: statistically significant compared to the nonsmokers $(p<0.05)$

Figure 2: Comparison of immune phenotypes in smokers and nonsmokers among anesthetic exposed subjects. The mean $\% \pm \mathrm{SE}$ are given for each group. 
Measured immune parameters did not change in the drinkers as compared to non drinkers (data not shown).We did not find significant changes in immune parameters when comparing anesthetic gas exposed to those personnel, who were exposed to X-rays as well as anesthetic gases. Furthermore, no changes were detected in lymphocyte subpopulations and activation, when we compared those personnel, who were potentially exposed to Halothane, to those, who worked in theaters where Halothane was not in use. There was, however, a significant decrease in the white blood cell count $(5.79 \pm 0.19 \mathrm{G} / \mathrm{L}$ and $6.49 \pm 0.27 \mathrm{G} / \mathrm{L}$ respectively, $\mathrm{p}=0.034)$ and the neutrophil count $(3.79 \pm 0.14 \mathrm{G} / \mathrm{L}$ and $4.38 \pm 0.22 \mathrm{G} / \mathrm{L}$ respectively, $\mathrm{p}=0.003)$ comparing Halothane exposed to non Halothane exposed.

No ambient air measurements were available for anesthetic gases, but it was known which departments had certified quality assurance at the time of the study. Those departments were certain to pay more attention to the safety measures and personal protection of personnel, and therefore it can be assumed that exposure to anesthetics was less than at those departments which had no quality assurance. Therefore, we compared data of that department which had quality assurance with those that did not and compared it to the control subjects (Figure 3). We found that the activation of lymphocytes increased where there was no quality assurance compared to both to those subjects where there was quality assurance and to the control. The percentage of CD25+/ CD3+ activated $\mathrm{T}$ cells and CD25+/CD4+ helper $\mathrm{T}$ cells increased compared to the aforementioned two groups, and the percentage of CD71+/CD19+ activated B cells increased compared to the subjects with quality assurance. Furthermore, the activation of lymphocytes in the quality assurance group did not differ significantly from the control group.

\section{Discussion}

Chemical exposure can alter the ratio of lymphocyte subpopulations and may cause changes in the activation of lymphocytes among oilindustry, health-service, and metallurgy workers and thus specific immunological markers can be monitored to assess exposure $[9,10]$. In a previous study, we have found an increase in immune alterations in hospital staff exposed to cytostatics, formaldehyde and anesthetics compared to the unexposed controls. In anesthetic-gas-exposed nurses, the use of protective measures resulted in the decrease of immune alterations [20].

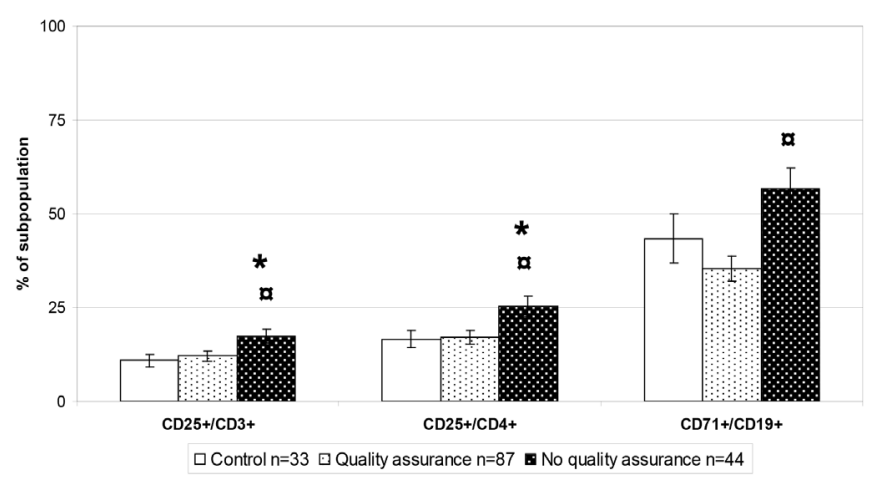

*: statistically significant compared to personnel with quality control $(p<0.05)$ d: statistically significant compared to the controls $(p<0.05)$

Figure 3: The effect of protective measures (quality assurance) on activation of lymphocytes in anesthetic exposed personnel. The mean $\% \pm$ SE are given for each group.
Cytostatic exposed health personnel had a significantly elevated $\mathrm{B}$ cell percentage and a decreased frequency of $\mathrm{CD} 25+/ \mathrm{CD} 4+\mathrm{T}$ cells compared to the nonexposed controls [21]. The decrease in the activation of lymphocytes is characteristic of cytostatic exposure in our experience, while most exposures are characterized by an elevation in the activation of $\mathrm{T}$ and/or $\mathrm{B}$ cells, although there is a difference in the expressed activation markers [1,2].

In the health personnel exposed to anesthetic gases we have found an elevation of CD25+ activated cytotoxic T cells (CD25+/CD8+ cells). The role of the CD8+ T cells is to monitor all the cells of the body, ready to destroy any that is considered to be a threat to the integrity of the host; for example, cytotoxic T cells kill virally infected cells, preventing them from being the source of more viral pathogen. Moreover, they are also thought to provide some degree of protection against spontaneous malignant tumors, by virtue of their ability to detect quantitative and qualitative antigenic differences in transformed cells (for review, see [22]).

In accordance with some of the literature [14-16], we did not find alterations in the percentages of $\mathrm{T}$ or B-lymphocytes in anesthetic exposed subjects. However, in anesthetic personnel exposed to occupational concentrations of Halothane and Nitrous oxide 10-60 times greater than the advised maximum, percentages of CD2 and CD4 T lymphocytes increased significantly, while percentage of NK cells decreased significantly during exposure. B-lymphocytes were most strongly affected: they decreased during working periods and did not recover after holidays [18]. On the other hand, chronic exposure to trace amounts of Nitrous oxide and Isoflurane in a group of relatively young anesthetists, negatively affected percentages of $\mathrm{T}$ lymphocytes. Furthermore, percentages of $\mathrm{T}$ helper cells decreased significantly according to the individual exposure score [19]. From these studies, the conclusion can be drawn that the exposing agent and the exposure level causes the differences in findings. This conclusion can be drawn from our results as well, as we found that in workplaces where there were not proper protective measures, the activation of lymphocytes was significantly increased compared to personnel with protective measures.

We examined the effect of X-ray exposure in addition to the volatile anesthetics, compared to only anesthetic exposure, but found no differences in the measured parameters. Unlike Bargellini et al. [19], who report that X-Ray exposure was clearly associated with stimulation of NK lymphocytes, and NK cell percentages were significantly higher in anesthetists regularly working in operating rooms under X-rays compared to non-exposed anesthetists.

Furthermore, in our study the lymphocyte subpopulations and activation of $\mathrm{T}$ and $\mathrm{B}$ cells did not differ in anesthetists with additional Halothane usage compared to non-Halothane using operating theater personnel, although it affected leukocyte counts.

We assessed the effect of smoking (active smokers compared to never smokers) on immune parameters among the anesthetics exposed, and found changes in leukocyte counts. We also found a shift in T cells subpopulations, leading to an elevated ratio of $\mathrm{Th} / \mathrm{Tc}$, which is in good agreement with our own findings $[9,21]$ and the literature. Freedman et al found that of the lymphocyte subsets, smokers had higher adjusted counts of CD4+ lymphocytes than did nonsmokers [23]. The rise in the number of CD4+CD29+ helper-inducer T lymphocytes in smokers was significantly higher than that in non-smokers [24]. Moreover, according to Tollerud et al. cigarette smokers had a selective increase in CD4+ cells (helper-inducer T cells) compared with nonsmokers, 
Citation: Biró A, Tompa A (2013) Life Style Factors Influencing Immunotoxic Effects Detected on Peripherial Blood Lymphocytes of Health Personnel Exposed to Anesthetic Gas. Clin Exp Pharmacol S4: 004. doi:10.4172/2161-1459.S4-004

Page 4 of 4

resulting in a statistically significant increase in the CD4+/CD8+ (helper/suppressor) ratio [25].

We did not find any changes in the measured immune parameters in conjunction with alcohol intake, which in part might be attributed to the fact that the subjects in the study were light drinkers. In humans, an increase in absolute values of the CD3+ lymphocytes has been recently found after 30 days of moderate beer consumption [26]. Since moderate alcohol consumption has been suggested to have a beneficial impact on the immune system compared to alcohol abuse or abstinence, the link between alcohol consumption, immune response, as well as infectious and inflammatory processes remains controversial and not yet completely understood (for review see [27]).

In conclusion, occupational exposure to anesthetic gases may cause alteration in the immune system, which can lead to health disorders. Personnel often indicate fatigue and headaches, especially when occupational hygiene conditions are inadequate. More serious disorders such as reduced fertility and problems during pregnancy are mentioned [7]. Interindividual variability of immune parameters is high in human populations, so a change in a single immune test in an individual may not indicate increased susceptibility for disease [28]. Nevertheless, even a subtle alteration in an immunity biomarker in the whole population indicates immunotoxicity [11]. In our study, we have demonstrated that immunotoxicity caused by occupational anesthetic gas exposure manifests itself in the increased activation of cytotoxic $\mathrm{T}$ lymphocytes, and that quality controlled protective and safety measures can protect health personnel from exposure. We have also shown that smoking status of the exposed must be taken into account when assessing occupational exposures.

\section{References}

1. Guirguis SS, Pelmear PL, Wong L (1990) Health effects associated with exposure to anesthetic gases in Ontario hospital personnel. $\mathrm{Br} \mathrm{J}$ of Industrial Medicine 47: 490-497.

2. Bruce DL, Eide KA, Linde HW, Echkenhoff JE (1968) Causes of death among anesthesiologists- a 20-year old survey. Anestesiology 29: 565-569.

3. Doll R, Peto R (1977) Mortality among doctors in different occupations. Br Med J 1433-1436.

4. Bunker JP, Child CG, Davidson CS (1966) Possible association between anesthesia and postoperative hepatic necrosis. JAMA 197: 775-788.

5. Cascorbi HG (1981) Effects of anestetics on the immune system. In: Cottrell JE ed. Occupational hazards to operating room and recovery room personnel. Boston: Little Brown Co 69-75.

6. Zhiyi Zuo (2012) Are volatile anesthetics neuroprotective or neurotoxic? Medical Gas Research 2: 1-10.

7. Axelsson G, Rylander R (1982) Exposure to anesthetic gases and spontaneous abortions: response bias in apostal questionnaire study (1982) In J Epidemiol, 11: $250-256$.

8. Cohen EN, Bellvile JW, Brown BW (1971) Anesthesi, pregnancy and miscarriage-a study of operating room nurses and anesthetists. Anesthesiology 35: 343-347.

9. Biró A, Pállinger E, Major J, Jakab MG, Klupp T, et al. (2002) Lymphocyte phenotype analysis and chromosome aberration frequency of workers occupationally exposed to styrene, benzene, polycyclic aromatic hydrocarbons or mixed solvents. Immunol Lett 81: 133-140.

10. Biró A, Pállinger E, Falus A, Tompa A (2004) Immuntoxikológiai vizsgálatok alkalmazása a kockázati csoportok jellemzésében. Magyar Onkológia 48: 137139

11. Principles and Methods for Assessing Direct Immunotoxicity Associated with Exposure to Chemicals (1996) Environmental Health Criteria 180: 233.

12. Barker JP, Abdelatti MO (1997) Anaesthetic pollution. Potential sources, their identification and control. Anaesthesia. 52: 1077-83.

13. Raj N, Henderson KA, Hall JE, Aguilera IM, Harmer M, et al. (2003) Evaluation of personal, environmental and biological exposure of paediatric anaesthetists to nitrous oxide and sevoflurane. Anaesthesia, 58: 630-636

14. Salo M, Vapaavuori M (1976) Peripheral blood T- and B-lymphocytes in operating theatre personnel. $\mathrm{Br} \mathrm{J}$ Anaesth 48: 877-880.

15. Salo M, Eskola J, Nikoskelainen J (1984) T and B lymphocyte function in anaesthetists. Acta Anaesthesiol Scand 28: 292-295.

16. Karakaya A, Tunçel N, Yücesoy B, Akin M, Cuhruk H, et al. (1992) The effects of volatile anaesthetic agents on human immune system function via occupational exposure. Immunopharmacol Immunotoxicol 14: 251-259.

17. Atallah MM, Motawea AA, el-Chennawy FA, Atallah AF (1991) Immunologica assays following exposure to halothane in clinical usage. Eur J Anaesth 8: 459464.

18. Peric M, Vranes Z, Marusic M (1991) Immunological disturbances in anaesthetic personnel chronically exposed to high occupational concentrations of nitrous oxide and halothane. Anaesthesia 46: 531-537.

19. Bargellini A, Rovesti S, Barbieri A, Vivoli R, Roncaglia R, et al. (2001) Effects of chronic exposure to anaesthetic gases on some immune parameters Sci Total Environ. 270: 149-156.

20. Tompa A, Jakab M, Biró A, Magyar B, Fodor Z, et al. (2006) Chemical safety and health conditions among Hungarian hospital nurses. Ann. N.Y. Acad. Sci, 1076: 635-648.

21. Biró A, Fodor Z, Major J, Tompa A (2011) Immunotoxicity Monitoring of Hospital Staff Occupationally Exposed to Cytostatic Drugs. Pathol Oncol Res 17: 301 308.

22. Andersen MH, Schrama D, Thor Straten P, Becker JC (2006) Cytotoxic T cells J Invest Dermatol 126: 32-41.

23. Freedman DS, Flanders WD, Barboriak JJ, Malarcher AM, Gates L (1996) Cigarette smoking and leukocyte subpopulations in men. Ann Epidemiol 6: 299-306.

24. Tanigawa T, Araki S, Nakata A, Sakurai S (1998) Increase in the helper inducer (CD4+CD29+) T lymphocytes in smokers. Ind. Health 36: 78-81.

25. Tollerud DJ, Clark JW, Brown LM, Neuland CY, Mann DL, et al. (1989) The effects of cigarette smoking on T cell subsets. A population-based survey of healthy caucasians. Am Rev Respir Dis.139: 1446-1451.

26. Romeo J, Warnberg J, Nova E, Diaz LE, Gonzalez-Gross M, et al. (2007) Changes in the Immune System after Moderate Beer Consumption. Ann Nutr Metab 51: 359-366.

27. Romeo J, Wärnberg J, Nova E, Díaz LE, Gómez-Martinez S, et al. (2007) Moderate alcohol consumption and the immune system: a review. $\mathrm{Br} \mathrm{J}$ Nutr 98 Suppl 1: S111-S115

28. Schwenk M, Sack U, Esser C, Klein R (2007) Diagnostic relevance of the determination of lymphocyte subpopulations in environmental medicine. Int $\mathrm{J}$ Hyg Environ Health 210: 177-198.
This article was originally published in a special issue, Novel Developments in Immunopharmacology and Immunotoxicology handled by Editor(s). Dr. Yuliang Ma, Weill Cornell Medical College, USA 